\title{
Homöopathiestudien: alles nur Placebo?
}

\begin{abstract}
Kann es sein, dass der Placeboeffekt in klinischen Studien mit Homöopathika stärker ausgeprägt ist als in Studien mit konventionellen Arzneimitteln? Und zeigen diese Studien nur deshalb keine Wirksamkeit des Homöopathikums, weil der übermäBig stark ausgeprägte Placeboeffekt die Wirksamkeit verschleiert?
\end{abstract}

- Deutsche Forscher verglichen die GröBe der Placeboeffekte in 25 klinischen Studien von Homöopathika mit denen von konventionellen Arzneimitteln. Diagnosen, Therapiedauer und Schwere der Symptome stimmten in den Studien in etwa überein. In 13 Fällen war der Placeboeffekt in den Homöopathiestudien und in zwölf Fällen in den konventio- nellen Studien größer. Im Mittel fanden sich keine siginifikanten Differenzen.

\section{Kommentar}

Anhänger der Homöopathie haben postuliert, dass viele placebokontrollierte Homöopathiestudien deswegen negativ ausfallen, weil in diesen Studien die Placeboeffekte sehr erheblich sind. Das Fehlen einer Differenz wäre dann nicht verursacht durch die Unwirksamkeit des Homöopathikums, sondern durch die Überwirksamkeit des Placebos.

Diese These hat einiges für sich. Sie hat jedoch einen erheblichen Fehler: Sie stimmt nicht. Somit ist die plausibelste Erklärung für homöopathische Negativergebnisse, dass das Homöopathikum selbst nichts weiter als ein Placebo ist.

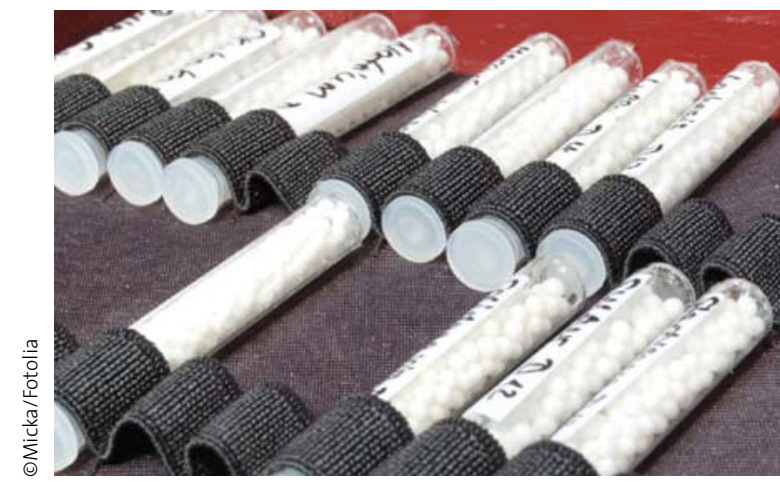

Am Placebo liegt's nicht, wenn Globuli nicht wirken.

- T. Nuhn, R. Lüdtke, M. Geraedts Placebo effect sizes in homeopathic compared to conventional drugs - a systematic review of randomised controlled trials. Homeopathy. 99 (2010) 76-82 